\title{
Electromagnetic safety of high voltage traction networks
}

\author{
Natalya Buyakova ${ }^{1 *}$, Vasilij Zakaryukin², Andrey Kryukov²,3 \\ ${ }^{1}$ Angarsk State Technical University, 665835, 60 Tchaikovsky St., Angarsk, Russia \\ ${ }^{2}$ Irkutsk State Transport University, 664074, 15 Chernyshevsky St., Irkutsk, Russia \\ ${ }^{3}$ Irkutsk National Research Technical University, 664074, 83 Lermontov St., Irkutsk, Russia
}

\begin{abstract}
The article provides procedure for simulation modeling of traction power supply systems which allows analyzing electromagnetic safety conditions in perspective high voltage traction networks. Modeling of electromagnetic fields in the Fazonord software application proved that $50 \mathrm{kV}$ traction system is characterized by the highest electromagnetic strength at a height of $1.8 \mathrm{~m}$ above the ground surface, while $2 \times 25 \mathrm{kV}$ system is characterized by the lowest one. Traditional traction system with $27.5 \mathrm{kV}$ voltage is the worst in terms of magnetic field strength, while $2 \times 50 \mathrm{kV}$ is the best; autotransformer systems of traction power supply create magnetic fields due to demagnetizing effect of power leads.
\end{abstract}

\section{Introduction}

Low-frequency electromagnetic fields (EMF) created by high voltage transmission lines and railroads traction networks can generate interference causing disturbances of electrical and electronic devices' normal functioning $[1,2]$ and result in serious personal injuries when operations are conducted on disconnected power supply lines or communication lines when personnel is subject to induced voltage.

The main effects are caused by $50 \mathrm{~Hz}$ electromagnetic fields on power facilities. Traction networks (TN) of alternating current electrified railroads are one of the major sources of EMF due to electromagnetic imbalance [3 - 11]. High voltage values can occur on accessory devices due to TN electromagnetic influence. Such voltages can result in, in the first turn, serious damage of the equipment and deadly electrocution cases. When the railroad track goes through a residential area, the levels of electromagnetic fields strengths (EMF) created by a electrical traction network, can, in a number of cases, exceed the permissible norms.

Operation modes of electrified railroad differ in complicated and non-linear dynamics which significantly hinders obtaining experimental data complying with EMF extreme voltage levels $[1,11]$. That is why, computer-based modeling methods are used to analyze electromagnetic safety conditions in traction power supply systems. Methods for modeling multi-wire power lines of electromagnetic fields, developed by the authors, allowed obtaining strengths quantitative assessments of electrical and magnetic fields created by traction net- works of alternating current electrified railroads [11 17]. Results of prospective high voltage traction systems modeling are given below.

\section{$294 \mathrm{kV}$ autotransformer traction networks}

The work [18] describes autotransformer traction power supplying system (TPSS) $94 \mathrm{kV}$ which can be used in electrification projects designed for new long-distance railroads and for reconstruction of the existing traction networks. In this TPSS main traction substations (TS) are equipped with balancing transformers, and intermediate substations are provided with one-phase transformers (fig. 1). Distance between main TS can reach $300 \ldots 350 \mathrm{~km}$.

On intermediate TS are located at a distance of $30 \ldots 45 \mathrm{~km}$ between each other, one-phase transformers with windings voltage 93.9/27.5 kV are installed. Balancing transformers can be supplied in two versions. In the first option, seven-winding transformer is used that has secondary windings connected as per triangles and incomplete stars circuits. In the second option fivewinding transformer is used; the secondary windings are designed for $66.4 \mathrm{kV}$ and $27.5 \mathrm{kV}$. The advantage of this transformer is that it can be connected with 'two wires rail' transmission line, however, the power of traction windings is one third higher in the second option, than in the first one. That is why seven-winding transformer should be preferred, which is further analyzed.

TPSS $94 \mathrm{kV}$ modeling was carried out in Fazonord software application [12], whose current version shall not contain more than five windings. That is consequent-

\footnotetext{
* Corresponding author: bn_900@mail.ru
} 
ly seven-winding transformer model is implemented as two four-winding transformers: 40000-230/66.4/66.4 and 40000-230/27.5/27.5. In addition, program software does not provides for asymmetrical windings modeling, that is why, for implementation of 'incomplete star' circuit, windings models were used that were connected as incomplete star, one lead of which was not used.

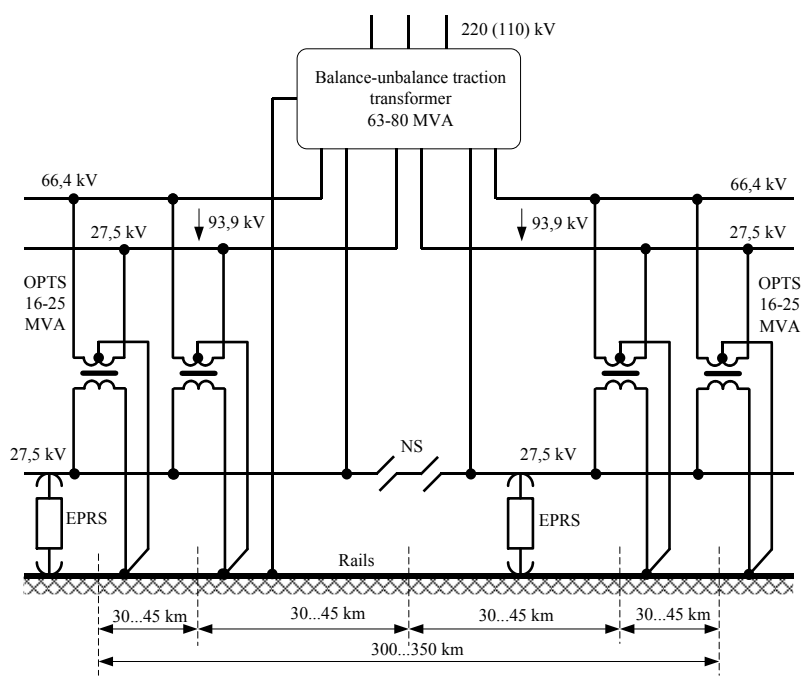

Fig. 1. High voltage TPSS diagram with balance-unbalance transformers: OPTS - one-phase traction substation: EPRS electrically-powered rolling stock; NS - neutral section

The modeled traction network included the following elements:

- wires PBSM-95+MF-100 of double-track road section overhead catenary;

- wire A-185 of $27.5 \mathrm{kV}$ line;

- wire A-185 of $66.4 \mathrm{kV}$ power line;

- four rail lines R-65.

In order to reduce traction network electrical influence, $66.4 \mathrm{kV}$ power wires were located above overhead catenaries.

Fazonord software application calculating circuit included models of balancing and one-phase transformers, multi-wire traction network section having $2 \mathrm{~km}$ length, and impedance bond with secondary winding which are needed to correctly determine current distribution in rail lines. Loads of $8+j 8$ MVA of each track were connected between the contact net and center tap of impedance bond.

Results of electrical and magnetic fields strengths at the beginning of traction network at a height of 1.8 from the ground surface for traction system options $27.5 \mathrm{kV}$ and $94 \mathrm{kV}$ are provided in fig. 2 and 3. XOY coordinate plane is perpendicular to railroad axis, origin of coordinates is located on the track axis, OY axis is perpendicular to the ground surface.

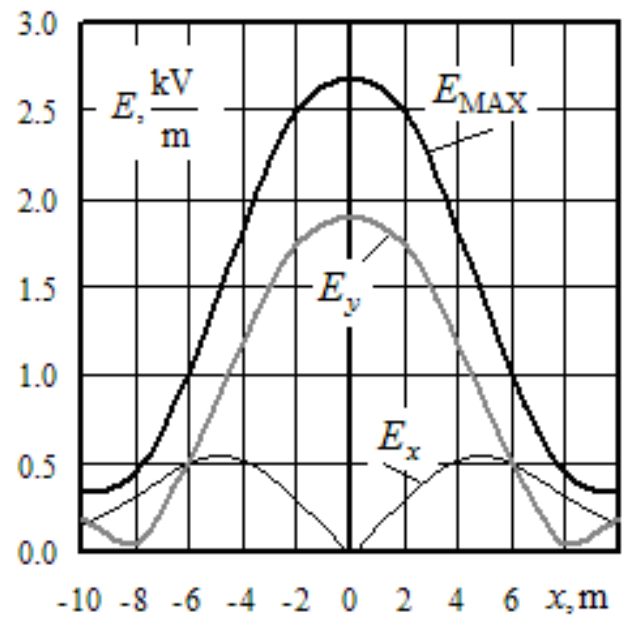

a)



b)

Fig. 2. Dependences of EMF strength components from $x$ coordinate for $94 \mathrm{kV}$ TPSS: a - electrical field; $\sigma$ - magnetic field

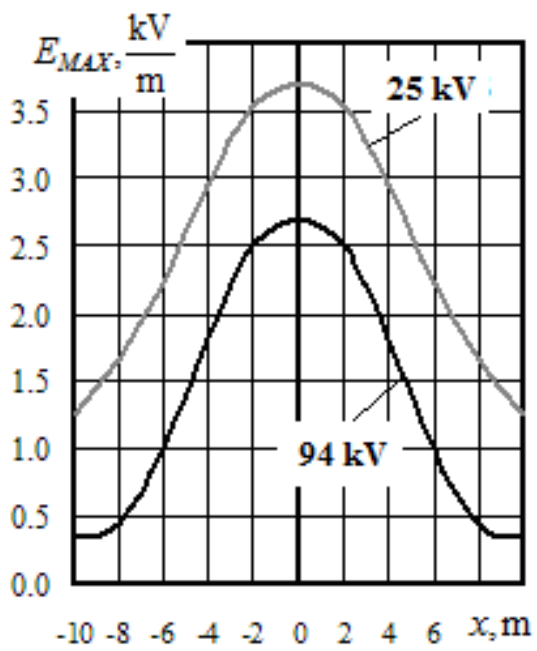

a) 


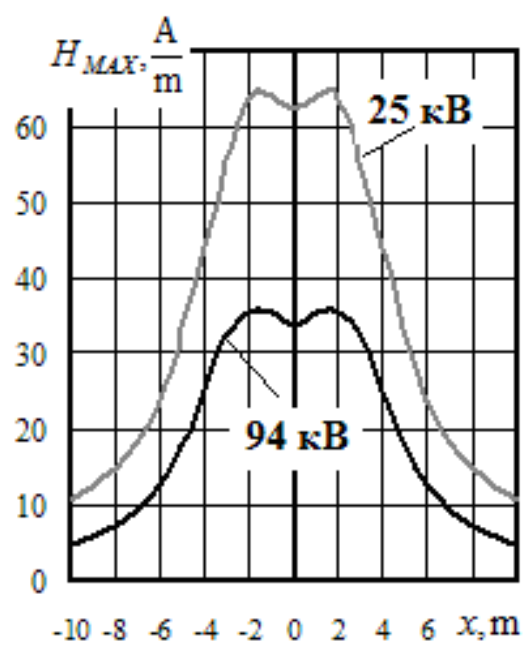

b)

Fig. 3. Dependences of EMF strength amplitude from the $x$ coordinate.

The modeling results allow formulation of the following conclusions.

1. Due to reducing effect of power wires, $94 \mathrm{kV}$ TPSS creates lesser EMF than the traditional $27.5 \mathrm{kV}$ TPSS

2. Perspective system of $94 \mathrm{kV}$ traction power supply ensures acceptable conditions of electromagnetic safety levels for railroad workers and population.

3. In points with coordinates $x=-10 \mathrm{~m}, y=1.8 \mathrm{~m}$ and $x=10 \mathrm{~m} y=1.8 \mathrm{~m}$, electrical field $94 \mathrm{kV}$ TPSS have linear polarization, whereas magnetic field - elliptic polarization. Such nature of magnetic field polarization is associated with return of a part of traction current through the ground and various inductances of direct and reverse current circuits.

\section{Traction networks with $50 \mathrm{kV}$ contact net}

Traction power supply systems with high voltage overhead catenaries are applied abroad: $50 \mathrm{kV}, 2 \times 50 \mathrm{kV}$ and $50+110 \mathrm{kV}$ [19]. Higher supply voltage of electricallypowered rolling stock enhances loading capability of traction power supply system, but can result in deterioration of the railroad electromagnetic conditions. Increase in voltage would lead to increase of electrical field strength, though, compared with $27.5 \mathrm{kV}$ system and comparable loads, magnetic field strength would decrease.

In order to perform quantitative analysis of the above factors, design study of high voltage traction networks $50 \mathrm{kV}, 2 \times 50 \mathrm{kV}$ and $50+110 \mathrm{kV}$ electromagnetic field structure was carried out.

\section{$3.150 \mathrm{kV}$ Traction network}

Traction transformer 40000/230/50, a $2 \mathrm{~km}$ section of double-track traction network, impedance bonds to calculate currents in rail lines and two dividing transformers with low losses to allow connection of loads between nodes and the earth were represented in the design model circuit.

Calculations of EMF voltages are given for doubletrack road section conditions when power of $8+j 8 \mathrm{MVA}$ is transmitted in each track road section traction network. TN parameters distribution was taken into account here and further.

The results are represented in fig. 4 where electrical and magnetic fields strengths profiles are depicted at a height of $1.8 \mathrm{~m}$ from the ground surface.

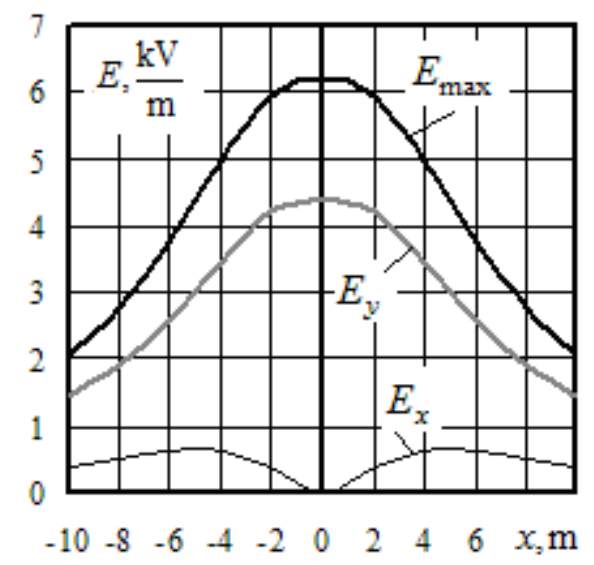

a)

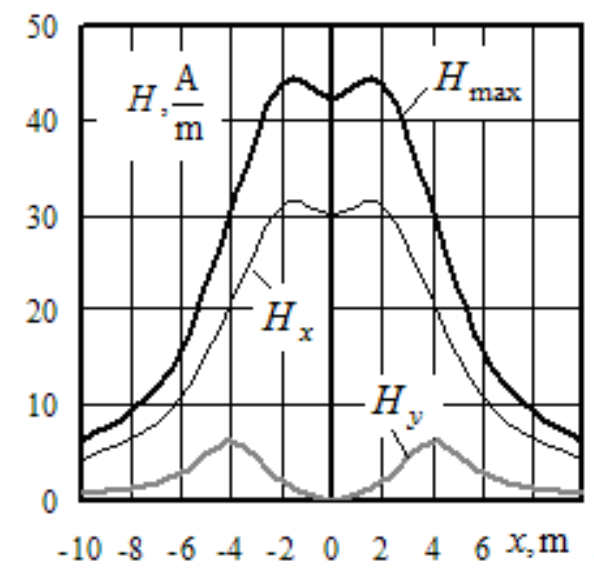

b)

Fig. 4. Dependences of EMF strength components of $50 \mathrm{kV}$ traction network from $x$ coordinate: $\mathrm{a}$ - electrical field; $\mathrm{b}-$ magnetic field

We can infer the following based on $50 \mathrm{kV}$ TPSS modeling results review:

1. Despite a high voltage at a height of $1.8 \mathrm{~m}$, electromagnetic safety conditions with regard to electrical field strength are not violated, strength effective value makes $4.4 \mathrm{kV} / \mathrm{m}$.

2. Magnetic field strength for 240 A of each track's overhead catenary does not exceed the permissible limits.

3. Electrical field has linear polarization, whereas magnetic field beyond the limits of the central zone, limited by X coordinate with location of overhead catenarys, is elliptically polarized which is associated with return of a significant current portion through the ground 
(390 A current flows through return feeder in the model, while $112 \mathrm{~A}$ - through the substation earth).

\section{$3.22 \times 50 \mathrm{kV}$ traction network}

Modeling circuit accepted for analysis included models of 25000/230/50/50 one-phase transformer and $16000 / 110$ autotransformers. TPSS $2 \times 50 \mathrm{kV}$ traction network differs from $50 \mathrm{kV}$ network in that it has power wires.

Results of electromagnetic field modeling at a height of $1.8 \mathrm{~m}$ for double-track road section loads $8+j 8$ MVA each, are given in fig. 5 .

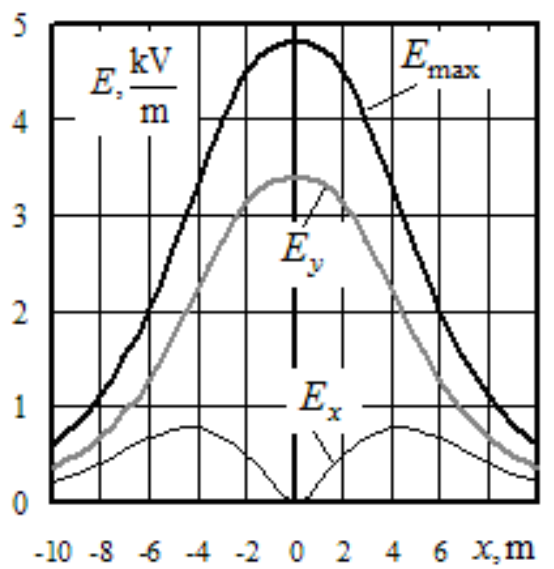

a)

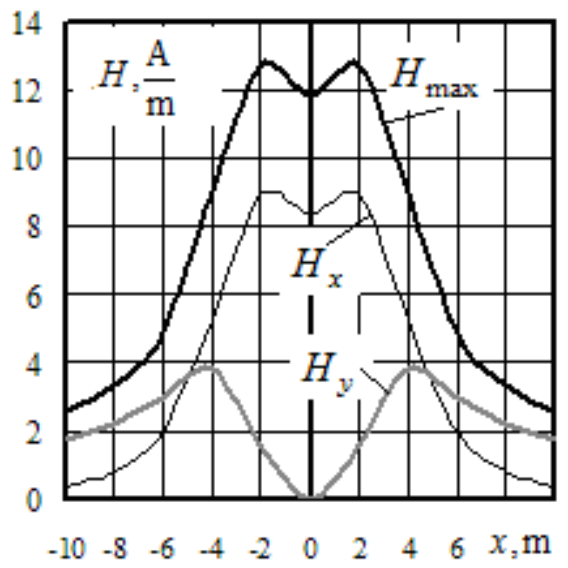

b)

Fig. 5. Dependences of EMF strength components in $2 \times 50 \mathrm{kV}$ $\mathrm{TN}$ on $x$ coordinate: $\mathrm{a}$ - electrical field; $\mathrm{b}$ - magnetic field

The results provided are, in the first turn, subject to the fact that the main flow of electromagnetic energy is concentrated within an interval between the power wires and its tracks overhead catenaries. It is due to this fact, that electrical and magnetic fields strengths do not exceed electromagnetic safety regulatory values at a height of $1.8 \mathrm{~m}$, and fields polarization is virtually linear due to low ground currents.

\section{$3.350+110 \mathrm{kV}$ traction network}

Traction network circuit for $50+110 \mathrm{kV}$ voltages differs from $2 \times 50 \mathrm{kV}$ network only in transformer parameters.
The design model contained one-phase traction transformer having power $25000 \mathrm{kV} \cdot \mathrm{A}$ with voltages $230 / 115 / 55 \mathrm{kV}$ and autotransformers with power 16000 $\mathrm{kV} \cdot \mathrm{A} 110 / 50 \mathrm{kV}$.

Results of electromagnetic field modeling at a height of $1.8 \mathrm{~m}$ for each track loads $8+j 8 \mathrm{MVA}$ each, are given in fig. 6 .

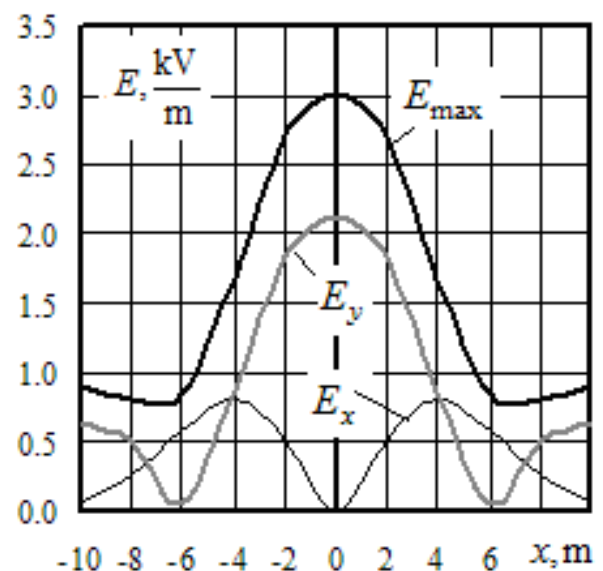

a)

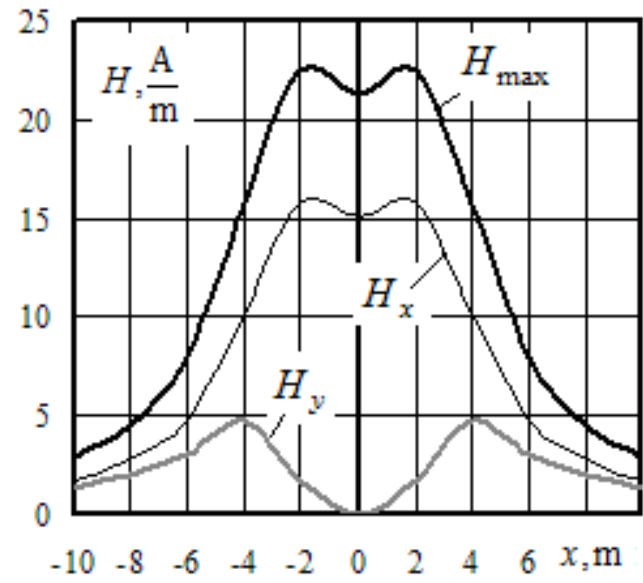

b)

Fig. 6. Dependences of EMF strength components in 50+100 $\mathrm{kV}$ TN on $x$ coordinate: a - electrical field; $\sigma$ - magnetic field

Modeling-based results are the following.

1. Electrical and magnetic fields strengths at a height of $1.8 \mathrm{~m}$ in the given operating mode of traction network do not exceed electromagnetic safety regulations.

2. Traction network electrical field at a height of 1.8 $\mathrm{m}$ has linear polarization, whereas magnetic field beyond the leads location is characterized by elliptical polarization. It is associated with irregular inductances of $110 \mathrm{kV}$ and $50 \mathrm{kV}$ circuits which result in different angular shift of currents in relevant wires.

\section{Comparison of high voltage traction networks}

Results of high voltage TPSS comparison by electrical safety criterion for similar loads at a height of $1.8 \mathrm{~m}$ from the ground surface are provided in fig. $7-10$. Dependences for $25 \mathrm{kV}$ traction power supply system are 
provided in fig. 7. Fig. 9, 10 are shown as comparison diagrams for all AC traction systems.

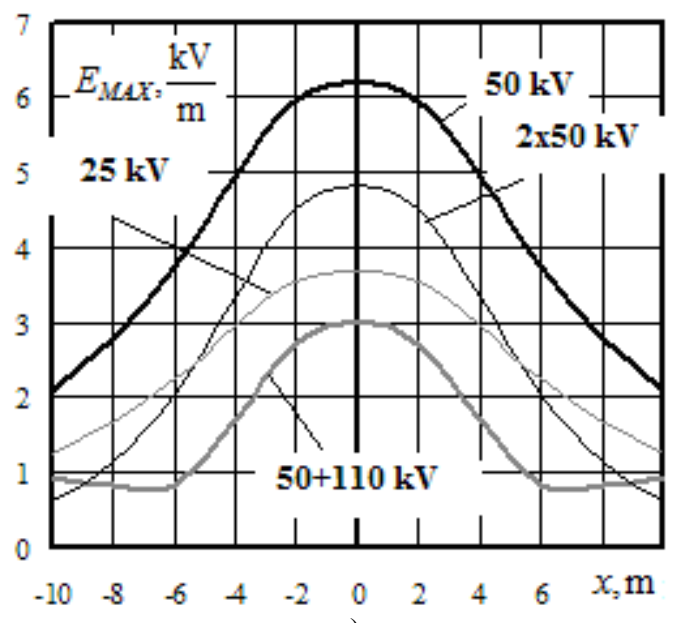

a)

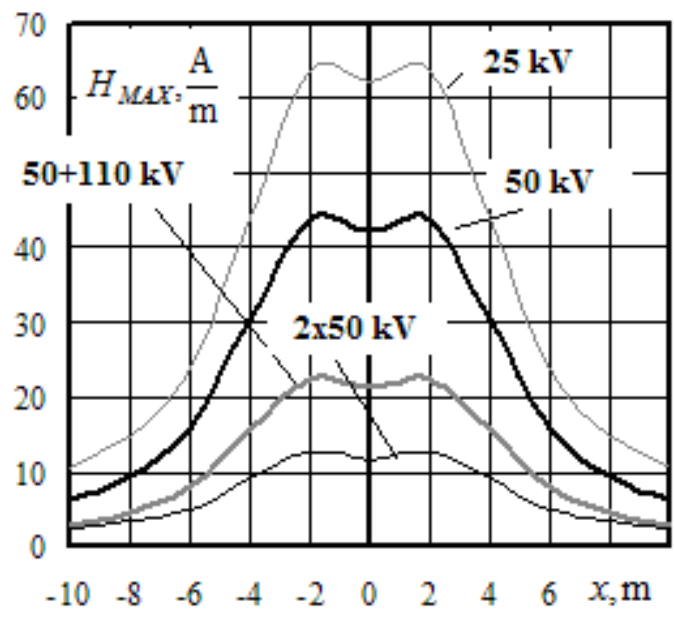

b)

Fig. 7. Dependences of EMF strengths amplitude from $x$ coordinate for systems with overhead catenary $50 \mathrm{kV}$ voltage. a electrical field; $\sigma$ - magnetic field

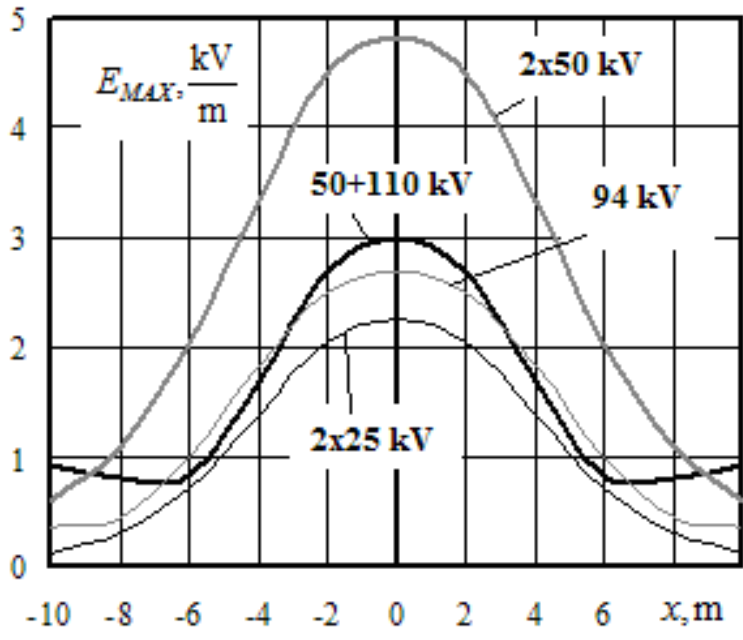

a)

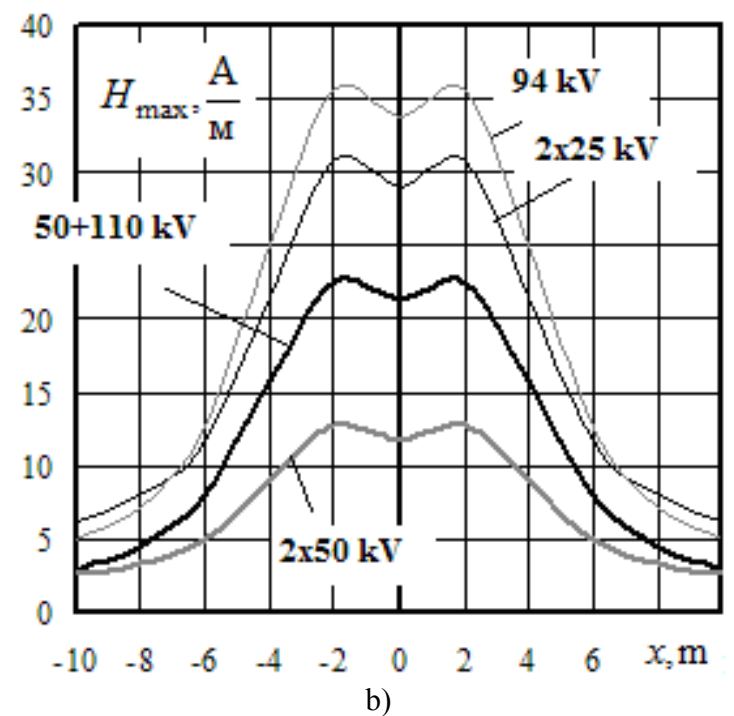

Fig. 8. Dependences of EMF strength amplitudes from $x$ coordinate for autotransformer systems: a - electrical field; 6 magnetic field

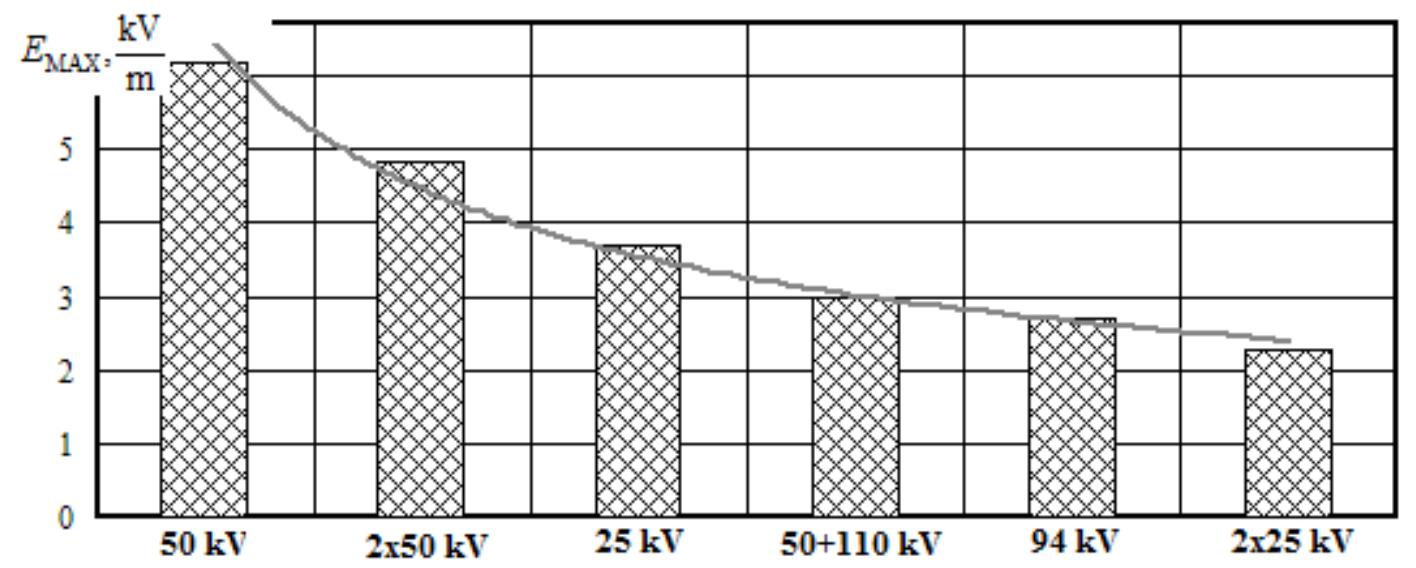

Fig. 9. Comparison of traction power supply by electric field strength 


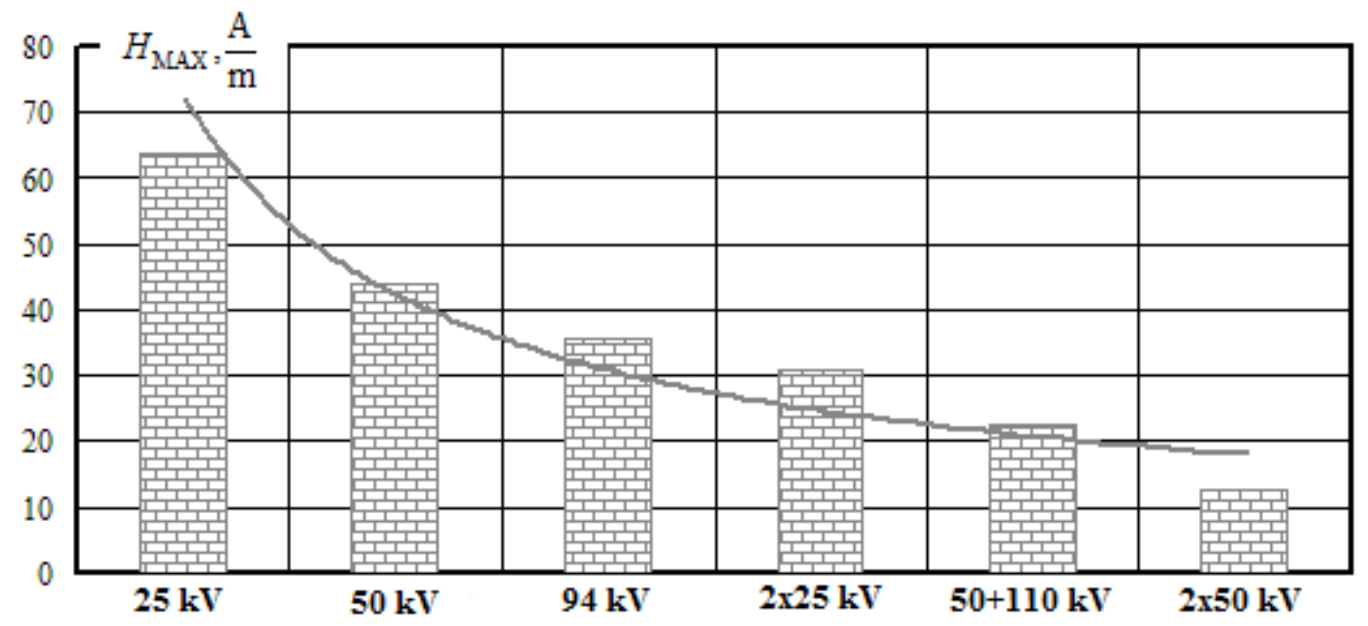

Fig. 10. Comparison of traction power supply systems by magnetic field strength

Comparison of different traction systems electromagnetic fields reveals the following:

- the highest electrical field strength at a height of $1.8 \mathrm{~m}$ above the ground surface is created by $50 \mathrm{kV}$ traction system, $2 \times 25 \mathrm{kV}$ system is characterized by the lowest strength;

- traditional traction system with $27.5 \mathrm{kV}$ voltage is the worst in terms of magnetic field strength, while $2 \times 50$ $\mathrm{kV}$ is the best; autotransformer systems of traction power supply create magnetic fields due to demagnetizing effect of power leads.

\section{Conclusions}

1. Due to reducing effect of power цшкуы to EMF, prospective traction power supply system $94 \mathrm{kV}$ creates lesser electromagnetic fields than the traditional $27.5 \mathrm{kV}$ TPSS. $94 \mathrm{kV}$ system ensures conditions of electromagnetic safety for railroad workers and population.

At $10 \mathrm{~m}$ distance from the track axis, at a height of $1.8 \mathrm{~m}, 94 \mathrm{kV}$ TPSS electrical field has linear polarization, while the magnetic one - elliptical polarization. Such magnetic field polarization is associated with return of a portion of traction current through the ground and with various inductances of direct and reverse current circuits.

2. Despite the stepped up voltage of $50 \mathrm{kV}$ traction network at a height of $1.8 \mathrm{~m}$, electromagnetic safety conditions with regard to electrical field strength are not violated. Magnetic field strength for 240 A of each track's overhead catenary does not exceed the permissible limits.

3. In $2 \times 50 \mathrm{kV}$ traction system at a height of $1.8 \mathrm{~m}$ electrical safety conditions with regard to electrical and magnetic fields strengths criteria, are complied with. In the first turn, this is subject to the fact that the main flow of electromagnetic energy is concentrated within an interval between the power wires and its tracks overhead catenaries.

4. In $50+110 \mathrm{kV}$ traction power supply system the strengths of electrical and magnetic fields at a height of $1.8 \mathrm{~m}$ do not exceed electrical safety regulations. Trac- tion network electrical field at a height of $1.8 \mathrm{~m}$ has linear polarization, whereas magnetic field beyond the wire locations is characterized by elliptical polarization. It is associated with different inductances of $110 \mathrm{kV}$ and 50 $\mathrm{kV}$ circuits which result in different angular shift of currents in relevant wires.

$5.50 \mathrm{kV}$ traction system is characterized by the highest electrical field strength at a height of $1.8 \mathrm{~m}$ above the ground surface, while $2 \times 25 \mathrm{kV}$ system is characterized by the lowest one. Traditional traction system with 27.5 $\mathrm{kV}$ voltage is the worst in terms of magnetic field strength, while $2 \times 50 \mathrm{kV}$ is the best; autotransformer systems of traction power supply create magnetic fields due to demagnetizing effect of power wires.

\section{References}

1. S. Apollonsky, Issues of electromagnetic safety on electrified railroad. V. II. Electromagnetic safety on the railroad with alternating current in traction network (RUSAINS, Moskow, 2017)

2. A.I. Sidorov, I.S. Okrainskaya, Electromagnetic fields near ultrahigh voltage electrical installations. (Chelyabinsk, 2008)

3. A. Ogunsola, A. Mariscotti Electromagnetic Compatibility in Railways (London: Springer, 2013)

4. A. Ogunsola, U. Reggiani, L. Sandrolini. International Symposium on Electromagnetic Compatibility, EMC'09. (2009)

5. Sheilah Frey. Railway Electrification Systems \& Engineering (White Word Publications, Delhi, 2012)

6. H. Biesenack, E. Braun, G. George, etc. Energieversorgung elektrischer bannen (Wiesbaden: B.G. Teubner Verlag, 2006)

7. A. Steimel Electric traction motive power and energy supply. Basics and practical experience. (Munchen: Oldenbourg Industrieverlag, 2008)

8. R. Kircher, J. Klühspies, R. Palka, et al. Transportation Systems and Technology. 4(2) (2018) 
9. Luan Xiaotian, Zhu Haijing, Qiu Bo, Han Bochong. CUE2016-Applied Energy Symposium and Forum (2016)

10. M.P. Bader Electromagnetic compatibility (Moskow, 2002)

11. N. Buyakova, V. Zakaryukin, A. Kryukov Electromagnetic safety in railroads power supply systems: modelling and control (Angarsk, 2018)

12. V.P. Zakaryukin, A.V. Kryukov Complex asymmetrical modes of electrical systems (Irkutsk, 2005)

13. V.P. Zakaryukin, A.V. Kryukov. Power Technology and Engineering Vol. 49, no. 4 (2015)

14. V.P. Zakaryukin, A.V. Kryukov. Innovation \& Sustainability of Modern Railway - Proceedings of ISMR'2008 (2008)
15. N. Buyakova, V. Zaharukin, A. Kryukov. Advances in Intelligent Systems Research. Vol. 158. IWCI 2018 (2018)

16. Natal'ya Buyakova, Vasiliy Zakaryukin, Andrey Kryukov, Tu Nguyen. E3S, Web of Conferences 58, 01006(2018) RSES 2018 (2018)

17. N.V. Buyakova, V.P. Zakaryukin, A.V. Kryukov Advances in Engineering Research. Vol. 158. International Conference on Aviamechanical Engineering and Transport. (2018)

18. A.M. Vasilyansky, P.P. Mamoshin, G.B. Yakimov World's railroads. No. 8. (2002)

19. Kotelnikov A.V. Railroads electrification. World trends and prospects (Moskow, 2002) 